\title{
ANALISIS RISIKO PELAKSANAAN PEMBANGUNAN JALAN TOL BENOA - BANDARA - NUSA DUA
}

\author{
Ni Putu Mega Astiti ${ }^{1}$, I Nyoman Norken ${ }^{2}$, Ida Bagus Ngr. Purbawijaya
}

\begin{abstract}
Abstrak : Proyek jalan tol Benoa-Bandara-Nusa Dua adalah proyek pembangunan jalan tol pertama di Bali. Jalan tol ini menghubungkan wilayah Nusa Dua dan Kecamatan Denpasar dan kawasan Pelabuhan Benoa. Pembangunan jalan tol Benoa-Bandara-Nusa Dua ini diklaim sebagai pembangunan jalan tol tercepat di Indonesia karena diselesaikan dalam jangka waktu 14 bulan. Dengan waktu pelaksanaan pembangunan yang demikian singkat maka perlu dilakukan penelitian mengenai risiko-risiko yang timbul pada tahap pelaksanaan pembangunan jalan tol.

Adanya risiko-risiko yang timbul dalam pelaksanaan pembangunan jalan tol akan berdampak langsung terhadap biaya dan waktu pembangunan tersebut, sehingga perlu adanya suatu analisis risiko terutama yang termasuk dalam kategori risiko dominan untuk dapat dijadikan sebagai dasar pengambilan keputusan oleh pihak yang terkait untuk mengatasi konsekuensi negatif yang terjadi dalam pembangunan jalan tol. Penelitian ini dilakukan dengan cara wawancara dengan berbagai pihak yang expert dan mempunyai kompetensi dalam pelaksanaan pembangunan jalan tol untuk mengetahui bagaimana kemungkinan (likelihood) terhadap berbagai risiko dan untuk mengetahui seberapa besar pengaruh (consequences) risiko.

Jumlah risiko yang teridentifikasi dalam penelitian ini adalah sebnayak 54 risiko. Distribusi penerimaan risiko pelaksanaan proyek sebanyak 20 (37.04\%) risiko tergolong unacceptable, 23 (42.59\%) risiko tergolong undesirable, 9 (16.67\%) risiko tergolong acceptable, 2 $(3.7 \%)$ risiko tergolong negligible. Penanganan risiko (risk mitigation) hanya dilakukan pada risiko-risiko dominan yaitu risiko yang tergolong unacceptable dan undesirable. Mitigasi risiko dilakukan terhadap risiko unacceptable sebanyak 20 risiko. Mitigasi risiko undesirable 23 risiko. Berdasarkan hasil mitigasi ini selanjutnya dilakukan pengelolaan kepemilikan risiko (ownership of risk) kepada pihak-pihak yang terlibat dalam pelaksanaan pembangunan jalan tol.
\end{abstract}

Kata kunci : Risiko, Identifikasi Risiko, Penanganan Risiko, Pengelolaan Risiko

\section{RISK ANALYSIS OF TOLL ROAD CONSTRUCTION BENOA - AIRPORT - NUSA DUA}

\begin{abstract}
Benoa-Bandara-Nusa Dua toll road project is the first toll road project in Bali. This highway connects region Nusa Dua with Benoa Harbour area. Construction of toll roads-BenoaBandara-Nusa Dua is claimed as the fastest highway development in Indonesia as completed within 14 months. With time so short that the implementation of development it is necessary to research on the risks that arise in the implementation phase of the construction of the toll road

The existence of the risks that arise in the implementation of toll road construction will directly impact the cost and development time. It is necessary in order to study the risks that might occur notably members of the dominant risk category can be used as a basis for decision making by the parties concerned to overcome the negative consequences that occur in the construction of toll roads. The research was conducted by means of interviews with various parties and has expert competence in the implementation of toll road construction to determine how the possibility (likelihood) against a variety of risks and to determine how much influences (Consequences) risk.

The number of risks identified in this study was as many as 54 risks. The distribution of revenue risk of the project is a total of 18 (33.33\%) classified as unacceptable risk, $25(46.29 \%)$ classified as undesirable risk, $9(16.67 \%)$ classified as acceptable risk, $2(3.7 \%)$ classified as negligible risk. Handling risk (risk mitigation) is only performed on the dominant risks are risks that are categorized as unacceptable and undesirable. Risk mitigation conducted on a total of 18 risk unacceptable risk. 25 risk mitigation undesirable risk. Based on the results of this mitigation is then performed risk management ownership (ownership of risk) to the parties involved in the implementation of toll road construction project.
\end{abstract}

Keywords: Risk, Risk Identification, Risk Mitigation, Risk Management

\footnotetext{
${ }^{1}$ Mahasiswa Program Studi Magister Teknik Sipil, Program Pascasarjana Universitas Udayana.

${ }^{2}$ Staff Pengajar Program Studi Magister Teknik Sipil, Program Pascasarjana Universitas Udayana.
} 


\section{PENDAHULUAN}

\section{Latar Belakang}

Proyek jalan tol Benoa-Bandara-Nusa Dua merupakan proyek jalan tol pertama di Bali yang dibangun untuk dapat mengurai kemacetan sekitar wilayah Bypass Benoa, Bandara dan Nusa Dua.

Pembangunan jalan tol BenoaBandara-Nusa Dua ini diklaim sebagai pembangunan jalan tol tercepat di Indonesi karena diselesaikan dalam jangka waktu 14 bulan. Dengan waktu pelaksanaan pembangunan yang demikian singkat maka perlu dilakukan penelitian mengenai risikorisiko yang timbul pada tahap pelaksanaan pembangunan jalan tol. Penelitian terhadap risiko pelaksanaan pembangunan jalan tol Benoa-Bandara-Nusa Dua mengindikasikan bahwa kegiatan pelaksanaan pembangunan jalan tol memiliki risiko kegagalan yang perlu diperhatikan secara serius oleh kontraktor karena dampak dari risiko yang timbul akan menghambat serta merugikan pihak pelaksana proyek baik dari segi biaya dan waktu.

Untuk dapat menghindar risiko yang timbul maka diperlukan adanya suatu analisis risiko sehungga dapat diketahui risiko yang masuk dalam kategori dominan sehingga dapat dilakukan perencanaan yang matang agar dapat mengatasi dampak kerugian baik dari segi biaya maupun waktu dalam pembangunan jalan tol.

\section{Rumusan Masalah}

Berdasarkan uraian diatas yang menjadi permasalahan dalam penelitian ini adalah :

1. Risiko-risiko apa saja yang teridentifikasi pada pelaksanaan pembangunan jalan tol Benoa-Bandara - Nusa Dua?

2. Risiko-risiko apa saja yang termasuk kategori dominan dan bagaimana tingkat/derajat risiko pada pelaksanaan pembangunan jalan tol Benoa - Bandara - Nusa Dua?

3. Bagaimana tindakan mitigasi (risk mitigation) untuk meminimalkan dampak negatif yang mungkin terjadi pada pelaksanaan pembangunan jalan tol Benoa - Bandara - Nusa Dua?

4. Bagaimana pengalokasian kepemilikan risiko (ownership of risk) terhadap risiko-risiko dominan (major risk) dalam pelaksanaan pembangunan jalan tol Benoa - Bandara - Nusa Dua?

\section{Tujuan Penelitian}

Penelitian ini dilakukan untuk dapat mengidentifikasi berbagai risiko yang muncul pada tahap pembangunan jalan tol serta untuk mengetahui risiko apa saja yang termasuk dalam kategori dominan sehingga kemudian risiko tersebut dapat dimitigasi agar dapat mengurangi konsekuensi yang ditimbulkan dari risiko tersebut serta melakukan pengalokasian risiko pihak siapa yang bertanggung jawab terhadap risiko yang muncul.

\section{KAJIAN PUSTAKA}

Menurut pendapat Flanagan (1993) Manajemen risiko adalah sebuah sistem yang bertujuan untuk mengidentifikasi seluruh risiko yang dilakukan dalam kegiatan bisnis atau proyek yang dapat digunakan untuk mengatasi risiko yang kemungkianan akan terjadi, bagaimana tindakan mitigasi serta pengalokasian risiko tersebut.

\section{Identifikasi Risiko (Risk Identification)}

$$
\text { Menurut Godfrey (1996) }
$$

identifikasi risiko dapat dikelompokkan menjadi beberapa sumber risiko: 1 . Risiko politik (political), 2. Risiko lingkungan (environmental), 3. Risiko perencanaan (planning), 4. Risiko pemasaran (market), 5. Risiko ekonomi (economic), 6. Risiko anggaran modal (financial), 7. Risiko alam (natural), 8. Risiko proyek (project), 9. Risiko teknis (technical), 10. Risiko sumberdaya manusia (human), 11. Risiko kriminal (criminal) dan 12. Risiko keamanan/keselamatan (safety). Menurut Godfrey (1996) besarnya risiko dapat diketahui dari hasil kali kecenderungan/frekuensi (likelihood) dan konsekuensi risiko. Tabel 1 adalah tingkat dan skala frekuensi (Likelihood) Tabel 2 adalah tingkat dan skala konsekuensi.

Tabel 1 Tingkat dan Skala Frekuensi (Likelihood)

\begin{tabular}{|l|l|}
\hline Tingkat Frekuensi & Skala \\
\hline Sangat Sering & 5 \\
Sering & 4 \\
Kadang-Kadang & 3 \\
Jarang & 2 \\
Sangat Jarang & 1 \\
\hline
\end{tabular}


Sumber : Godfrey, (1996)

Tabel 2 Tingkat dan Skala Konsekuensi (Consequences)

\begin{tabular}{|l|l|}
\hline Tingkat Konsekuensi & Skala \\
\hline Sangat Besar & 5 \\
Besar & 4 \\
Sedang & 3 \\
Kecil & 2 \\
Sangat Kecil & 1 \\
\hline
\end{tabular}

Sumber : Godfrey, (1996)

\section{Penerimaan Risiko (Risk Acceptability)}

Analisis terhadap penerimaan risiko (risk acceptability) ditentukan berdasarkan nilai perkalian antara tingkat frekuensi dan tingkat konsekuensi risiko. Setelah diperoleh tingkat penerimaan risiko tersebut maka dapat diperoleh skala penerimaan risiko (risk acceptability) seperti tabel 3:

Tabel 3 Skala Penerimaan Risiko

\begin{tabular}{|l|l|}
\hline $\begin{array}{l}\text { Indikator Penerimaan } \\
\text { Risiko }\end{array}$ & $\begin{array}{l}\text { \$kala Penerimaan } \\
\text { Risiko }\end{array}$ \\
\hline Unacceptable & $\mathrm{X} \geq 15$ \\
Undesirable & $8 \leq \mathrm{X}<15$ \\
Acceptable & $3 \leq \mathrm{X}<8$ \\
Negligible & $\mathrm{X}<3$ \\
\hline
\end{tabular}

Sumber : Godfrey, (1996)

\section{Penanganan Risiko (Risk Mitigation)}

Mitigasi/penanganan adalah tindakan yang dilakukan untuk menghilangkan atau mengurangi risiko yang telah teridentifikasi. Adapun risiko yang tidak dapat dihilangkan sepenuhnya, namun hanya dapat dikurangi sehingga akan ada menimbulkan risiko sisa.

\section{METODE PENELITIAN}

\section{Rancangan penelitian}

Penelitian dilakukan pada Proyek pembangunan jalan tol Benoa - Bandara Nusa Dua dengan metode penelitian deskriptif kualitatif. Metode yang digunakan dalam penelitian deskriptif kualitatif. Permasalahan diperoleh dengan metode wawancara dan survey untuk mendapatkan pendapat atau opini dari responden dan expert dalam pembangunan jalan tol.

\section{Lokasi Obyek Penelitian}

Lokasi proyek pembangunan jalan tol Benoa - Bandara - Nusa Dua ini menghubungkan wilayah selatan Pulau Bali (Nusa Dua) dengan wilayah Kecamatan Denpasar Selatan, tepatnya kawasan Pelabuhan Benoa dan akses menuju ke Bandara Internasional Ngurah Rai.

\section{Teknik Pengumpulan Data}

Teknik pengumpulan data pada penelitian ini adalah sebagai berikut :

1. Pengumpulan Data Primer dari penelitian ini diperoleh dari data opini responden. Identifikasi risiko yang dihasilkan dari pengkajian data sekunder (penelitian terdahulu, jurnal, laporan-laporan, dan literatur) kemudian dikembangkan dengan pengamatan/investigasi lapangan dan melakukan wawancara serta brainstorming dengan pihak yang berkompetensi dan berpengalaman di bidang pembangunan jalan khususnya jalan tol.

2. Pengumpulan Data Sekunder diperoleh dari paper penelitian, jurnal, laporanlaporan dan literature sesuai dengan objek penelitian untuk memperoleh identifikasi awal risiko.

\section{Uji Instrumen Penelitian}

Suatu data dikatakan valid jika ada korelasi dengan skor total. Hal ini menunjukkan adanya dukungan data tersebut dalam mengungkapkan sesuatu yang ingin diteliti. Uji reliabilitas merupakan kelanjutan dari uji validitas dimana item yang masuk pengujian adalah item yang valid saja. Reliabilitas diukur dari koefisien Alpha (Malhotra, 1999). Menurut Sekaran (1992), reliabilitas kurang dari 0,6 adalah kurang baik, sedangkan 0,7 dapat diterima, dan diatas 0,8 adalah baik.

\section{HASIL DAN PEMBAHASAN}

\section{Hasil Uji Validitas dan Reliabilitas}

Berdasarkan uji validitas dengan SPSS for Windows ver. 21 dengan teknik Produk Momen Pearson, diperoleh nilai koefisien korelasi setiap item pertanyaan nilainya melebihi 0.444 (nilai $\mathrm{r}$ tabel, 2tailed dengan signifikansi 0.05) maka dapat disimpulkan bahwa item-item pertanyaan dalam kuesioner memiliki kolerasi signifikan dengan skor total sehingga dapat disimpulkan bahwa item-item tersebut valid. 
diperoleh koefisien alpha (Crobach's Alfa) > 0.6 maka data tersebut dinyatakan reliabel.

\section{Analisis Identifikasi Risiko Pelaksanaan Pembangunan Jalan Tol Benoa - Bandara - Nusa Dua \\ Terdapat 54 risiko yang} teridentifikasi pada tahap pelaksanaan pembangunan jalan tol Benoa - Bandara Nusa Dua.

Analisis Penerimaan Risiko (Risk Acceptability) Pelaksanaan Pembangunan Jalan Tol Benoa - Bandara - Nusa Dua.

Hasil penerimaan risiko dapat dijelaskan sebagai berikut risiko yang tergolong unacceptable (tidak dapat diterima) sebanyak 20 risiko, risiko yang tergolong undesirable (tidak diharapkan) sebanyak 23 risiko, risiko yang tergolong acceptable (dapat diterima) sebanyak 9 risiko, dan risiko yang tergolong negligible (dapat diabaikan) sebanyak 2 risiko dapat dilihat pada gambar 1 .

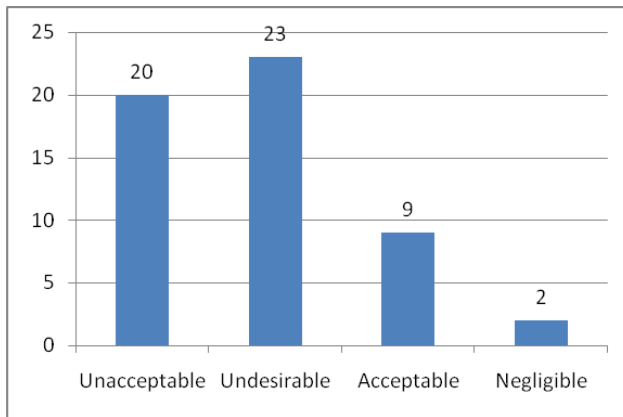

Gambar 1. Distribusi Penerimaan Risiko

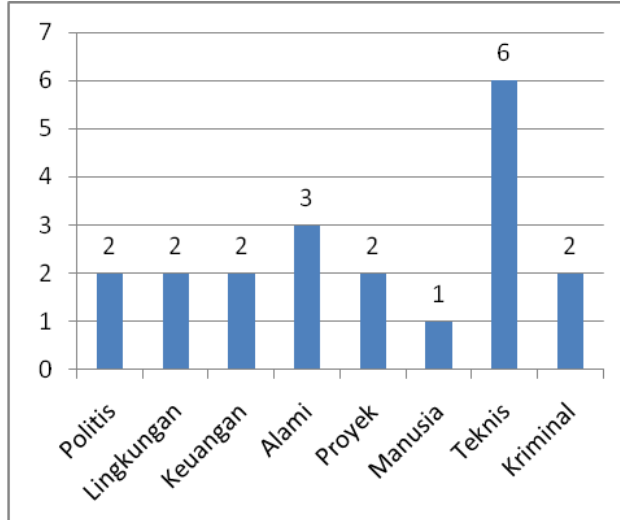

Gambar 2. Penerimaan Risiko Unacceptable

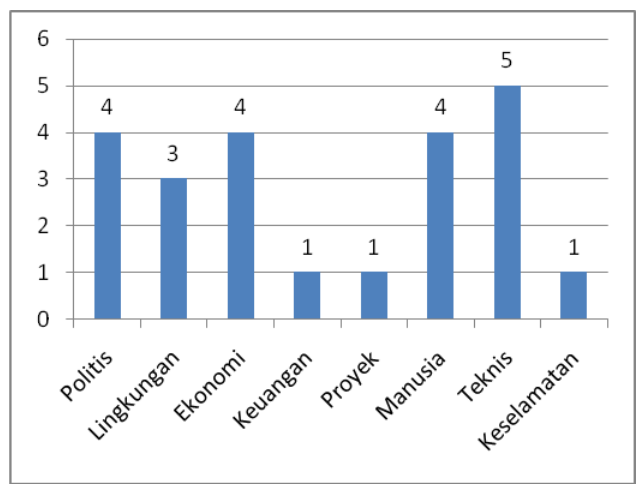

Gambar 3. Penerimaan Risiko Undesirable

\section{Mitigasi Risiko}

Mitigasi risiko (risk mitigation) dilakukan setelah diperoleh risiko yang memberikan dampak besar terhadap suatu aktivitas (Major Risk). Mitigasi risiko dapat dilakukan dengan menahan risiko (retention risk), mengurangi risiko (reduction risk), memindahkan risiko (risk transfer) dan menghindari risiko ( risk avoidance).

\section{Kepemilikan Risiko}

Adapun hasil alokasi risiko Unacceptable dan Undesirable dilihat pada Gambar dibawah ini:

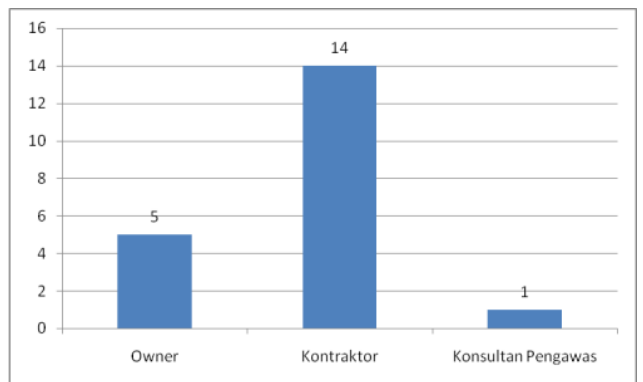

Gambar 4. Alokasi Kepemilikan Risiko Unacceptable

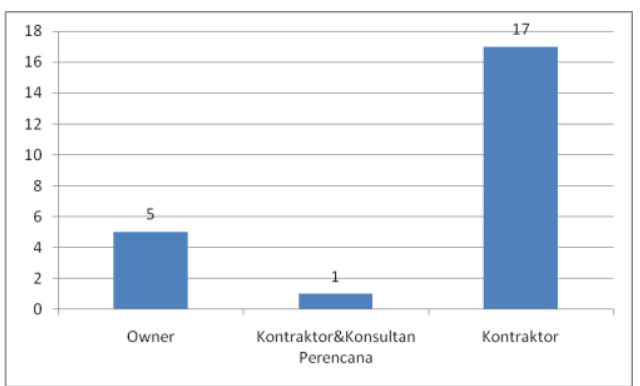

Gambar 5. Alokasi Kepemilikan Risiko Undesirable

\section{Simpulan}

1. Pada pelaksanaan pembangunan jalan tol Bandara - Benoa - Nusa Dua teridentifikasi 54 (lima puluh empat) risiko berdasarkan aktivitas pada tahap 
pelaksanaan proyek. Risiko yang teridentifikasi yaitu 7 (tujuh) risiko politis, 5 (lima) risiko lingkungan, 4 (empat) risiko ekonomi, 6 (enam) risiko keuangan, 4 (empat) risiko alami, 4 (empat) risiko proyek, 6 (enam) risiko manusia, 13 (tigabelas) risiko teknis, 3 (tiga) risiko kriminal, dan 2 (dua) risiko keselamatan). Kemudian setelah melakukan identifikasi risiko dilakukan analisis penerimaan risiko yaitu 20 (dua puluh) risiko kategori tidak dapat diterima (unacceptable), 23 (dua puluh tiga) risiko yang masuk dalam kategori tidak diharapkan (undesirable), 9 (Sembilan) risiko yang masuk kategori dapat diterima (acceptable), dan 2 (dua) risiko yang masuk kategori dapat diabaikan (negligible).

2. Risiko dengan kategori dominan (major risk) yaitu 43 (empat puluh tiga) risiko terdiri dari 20 (dua puluh) risiko yang tidak dapat diterima (unacceptable). Risiko yang termasuk dalam kategori unacceptable ini harus mendapat perhatian khusus karena apabila tidak ditangani dengan baik akan berdampak besar terhadap proyek. Risiko undesirabl sebanyak 23 (dua puluh tiga) risiko. Risiko teknis paling banyak teridentifikasi.

3. Tindakan mitigasi risiko dilakukan untuk mengurangi dampak negatif dari risiko-risiko yang termasuk dalam kategori risiko dominan (major risk). Untuk risiko yang termasuk kategori tidak dapat diterima (unacceptable) dilakukan 32 (tiga puluh dua) tindakan mitigasi, sedangkan risiko yang termasuk dalam kategori undesirable terdapat 24 (dua puluh empat) mitigasi risiko.

4. Kepemilikan risiko terhadap pihak yang langsung terhubung dalam pelaksanaan pembangunan jalan tol Benoa - Bandara - Nusa Dua yaitu Owner (PT. Jasa Marga Bali Tol), konsultan pengawas, dan kontraktor selaku pelaksana proyek. Dari hasil penelitian menunjukkan untuk risiko yang termasuk dalam kategori unacceptable terdapat 5 risiko yang menjadi tanggung jawab owner, dan 14 risiko yang menjadi tanggung jawab kontraktor selaku pelaksana proyek dan 1 risiko menjadi tanggung jawab konsultan perencana. Sedangkan untuk risiko yang termasuk dalam kategori undesirable terdapat 5 risiko yang menjadi tanggung jawab owner, 1 risiko yang menjadi tanggung jawab kontraktor dan konsultan pengawas, 1 risiko yang menjadi tanggung jawab konsultan perencana, dan 17 risiko yang menjadi tanggung jawab kontraktor.

\section{UCAPAN TERIMA KASIH}

Ucapan terima kasih disampaikan kepada pihak-pihak yang membantu menjawab kuesioner yang disebarkan dan seluruh pihak yang membantu dalam penulisan.

\section{DAFTAR PUSTAKA}

Darmawi, H. 2006. Manajemen Risiko. Cetakan kesepuluh. Jakarta : Bumi Aksara.

Djarwanto. 2001. Pokok-pokok Analisa Laporan keuangan. Yogyakarta; BPFE.

Eriyanto. 2007. Teknik Sampling Analisis Opini Public. Jogjakarta ; Pelangi Aksara.

Flanagan, R. dan Norman, G. 1993. Risk Management and Construction. Cambridge : University Press.

Godfrey, P.S., Sir William Halcrow and Partners Ltd. 1996. Control of Risk A Guide to Systematic Management of Risk from Construction. Wesminster London : Construction Industry Research and Information Association (CIRIA).

Kezner, H. 1995. Project Management A System Approach to Planning Scheduling and Controlling. Fifth edition. New York : Van Nostrand Reinhold.

Mahadipta, N. G. 2010. “Analisis Risiko Pada Proyek Pembangunan Sentral Parkir di Pasar Badung" (tesis). Denpasar; Universitas Udayana.

Nunnally, J. (1967). Psychometric Methods. New York. McGraw-Hill.

Norken, I Nyoman. 2012, Manajemen Risiko Pada proyek Konstruksi di Pemerintah Kabupaten Jembrana, Vol. 16; No. 2.

Purbawijaya, I. B. N. 2011. Manajemen Risiko Penanganan Banjir Pada Sistem Jaringan Drainase di Wilayah Kota Denpasar. Vol 15; No.1.

Ruslan, Rosady. 2003. Metode Penelitian Public Relation dan Komunikasi. Jakarta; PT. Raja Grafindo Persada. 
Sandhyavitri, dkk. "Analisis Risiko Jalan Tol Tahap Pra Konstruksi (Studi Kasus: Jalan Tol Pekanbaru Dumai)" (tesis). Pekanbaru; Universitas Riau.

Sugiyono. 2004. Metode Penelitian Kuantitatif, Kualitatif dan R\&D. Bandung: Alfabeta.

Thompson, P.A. dan Perry, J.G. 1991. Engineering Construction Risk. London : Thomas Telford Ltd.

Vaughan, E. J. 1978. Fundamental of Risk and Insurance. Second Edition. John Willey.

Wardana, S. W. 2012. Pembebasan Tanah Jalan Tol. Available from: URL: http://wisnu.blog.uns.ac.id/2012/07/ 02/pembebasan-tanah-jalan-tol/

Wirawan, Nata. 2001, Cara Mudah Memahami Statistik Deskiptif \& Inferensia, Denpasar: Penerbit Keraras Emas 